\title{
Diagnostic Approaches to Sjögren's Syndrome: a Literature Review and Own Clinical Experience
}

\author{
Pedro de Sousa Gomes ${ }^{1}$, Gintaras Juodzbalys ${ }^{2}$, Maria Helena Fernandes ${ }^{1}$, Zygimantas Guobis ${ }^{3}$ \\ ${ }^{1}$ Laboratory of Pharmacology and Cellular Biocompatibility, Faculty of Dental Medicine, University of Porto, Porto, Portugal. \\ ${ }^{2}$ Department of Maxillofacial Surgery, Medical Academy, Lithuanian University of Health Sciences, Kaunas, Lithuania. \\ ${ }^{3}$ Department of Dental and Oral Pathology, Medical Academy, Lithuanian University of Health Sciences, Kaunas, Lithuania.
}

\author{
Corresponding Author: \\ Pedro de Sousa Gomes \\ Laboratory of Pharmacology and Cellular Biocompatibility \\ Faculty of Dental Medicine, University of Porto \\ Rua Dr. Manuel Pereira da Silva \\ 4200-393 Porto \\ Portugal \\ Tel. +351220901100 \\ Fax. +351220901 101 \\ E-mail:pgomes@,fmd.up.pt
}

\begin{abstract}
Objectives: The purpose of present paper is to critically address the recent advances on diagnostic procedures of Sjögren's syndrome, taking into account the attained local and systemic features of the disease.

Material and Methods: A comprehensive review of the available literature regarding to the diagnostic approaches to Sjögren's syndrome was conducted. Eligible studies were identified by searching the electronic literature PubMed, Medline, Embase, and ScienceDirect databases for relevant reports (last search update January 2012) combining the MESH heading term "Sjögren's syndrome", with the words "diagnosis, diagnostic procedures, salivary gland function, ocular tests, histopathology, salivary gland imaging, serology". The authors checked the references of the selected articles to identify additional eligible publications and contacted the authors, if necessary.

Results: Presented article addresses the established diagnostic criteria for Sjögren's syndrome and critically evaluates the most commonly used diagnostic procedures, presenting data from author's own clinical experience. Diagnostic criteria for Sjögren's syndrome are required both by healthcare professionals and patients, namely in order to provide a rational basis for the assessment of the symptoms, establish an individual disease prognosis, and orientate the therapeutic intervention.

Conclusions: Sjögren's syndrome is quite a common autoimmune disease of which the diagnosis and treatment are not easily established. Due to its systemic involvement, it can exhibit a wide range of clinical manifestations that contribute to confusion and delay in diagnosis. The use of proper diagnostic modalities will help to reduce the time to diagnosis and preserve the health and quality of life of patients with Sjögren's syndrome.
\end{abstract}

Keywords: Sjogren's syndrome; oral pathology; salivary glands; xerostomia; xerophthalmia; salivary glands, minor; diagnosis.

Accepted for publication: 20 March 2012

To cite this article:

Gomes PD, Juodzbalys G, Fernandes MH, Guobis Z. Diagnostic Approaches to Sjögren's Syndrome: a Literature Review and Own Clinical Experience.

J Oral Maxillofac Res 2012 (Jan-Mar);3(1):e3

URL: http://www.ejomr.org/JOMR/archives/2012/1/e3/v3n1e3ht.pdf

doi: $10.5037 /$ jomr.2012.3103 


\section{INTRODUCTION}

Sjögren's syndrome (SS) is quite a common autoimmune disease evidenced by broad organ-specific and systemic manifestations. The most prevalent symptoms are diminished lacrymal and salivary gland function, xerostomia and keratoconjunctivitis sicca [1]. In addition, symptoms do not always occur concurrently. Primary SS (pSS) presents alone, and secondary SS (sSS) occurs in connection with other autoimmune rheumatic disease. This diversity of symptomatic expression adds to the difficulty in the initial diagnosis, and to the identification of homogenous group of patients with a uniform aetiopathogenesis or prognosis. The purpose of present paper is to critically address the recent advances and own clinical opinion on diagnostic procedures of Sjögren's syndrome, taking into account the attained local and systemic features of the disease.

\section{MATERIAL AND METHODS}

A comprehensive review of the available literature between 1970 and 2012, regarding to the diagnostic approaches to SS was conducted. Eligible studies were identified by searching the electronic literature PubMed, Medline, Embase, and ScienceDirect databases for relevant reports (last search update January 2012), combining the MESH heading term "Sjögren's syndrome", with the words "diagnosis, diagnostic procedures, salivary gland function, ocular tests, histopathology, salivary gland imaging, serology". The authors checked the references of the selected articles to identify additional eligible publications and contacted the authors, if necessary. Present article addresses the established diagnostic criteria for SS and critically evaluates the most commonly used diagnostic procedures. However, it is not possible to comprehensively discuss every subject, because that would require a text too extensive for a single article. When appropriate, references are cited.

\section{Diagnosis of Sjögren's syndrome}

The early and accurate establishment of a correct diagnosis of SS can assist on the prevention and timely treatment of many complications associated with the disease's natural course.

Although minor salivary gland biopsy has been traditionally considered "the gold standard" for the diagnosis of SS, newer criteria have emerged to assist on this disease identification. In 1993, the Preliminary European Classification criteria for
SS were proposed and have been widely used, both in research and in clinical practice [2]. Later on, in 2002, the criteria were re-examined and the revised version, published by the American Consensus Group, has led to the "American-European Consensus Group Criteria - revised international classification criteria for Sjögren's syndrome" criteria set [ $\underline{3}]$. The established criteria became the most used tool in clinical trials and epidemiological surveys, addressing the classification of SS, both in primary and secondary entities. Moreover, due to addressed high sensitivity and specificity, they also became of clinical use in the diagnosis of the disease [4]. The classification system is presented on Table 1. In this score, 6 different items for each patient are considered (ocular symptoms, oral symptoms, eye tests, lip biopsy, imaging or function investigation of the salivary glands and antibodies in the blood) and if 4 or more items are positive, the patient is considered to fulfil the classification criteria for SS. Interestingly, some particular diagnostic difficulties can arise from the use of this classification system. For instance, a patient who does not meet the criteria for salivary gland involvement and does not report both eye signs and eye symptoms, even in the situation of the fulfilment of 4 items, would be better classified as having a focal lymphocytic sialadenitis, instead of SS. Comparing the patients who only report ocular and oral signs and symptoms, and have been diagnosed as having keratoconjunctivitis sicca and xerostomia might be overdiagnosed with SS.

An alternative classification for diagnosing SS was proposed by a Japanese expert group. This has been initially published in the late 1970's, and revised in 1999 [5]. These criteria, being mainly objective, address four major areas: histopathology, oral examination, ocular examination, and serological examination. The classification system is presented on Table 2 .

The diagnosis of SS can be made when the patient meets at least two of these four criteria. These criteria have been shown to report a high sensitivity, specificity and accuracy for diagnosing SS []ㅡ.

Following, the major signs, symptoms and tests commonly used for the diagnosis of SS are presented and critically appraised.

\section{Ocular and oral symptoms}

Symptoms from the eyes (item I) and from the oral cavity (item II) are highly regarded in the American-European Consensus Group Criteria for SS diagnosis. In these criteria, by responding affirmatively to at least one of the three predefined questions for the function of each exocrine gland, two items are readily checked positive. This means that 2 out of 4 items, half of the requirements 
Table 1. Revised international classification criteria for Sjögren's syndrome, by the American-European Consensus Group Criteria, 2002

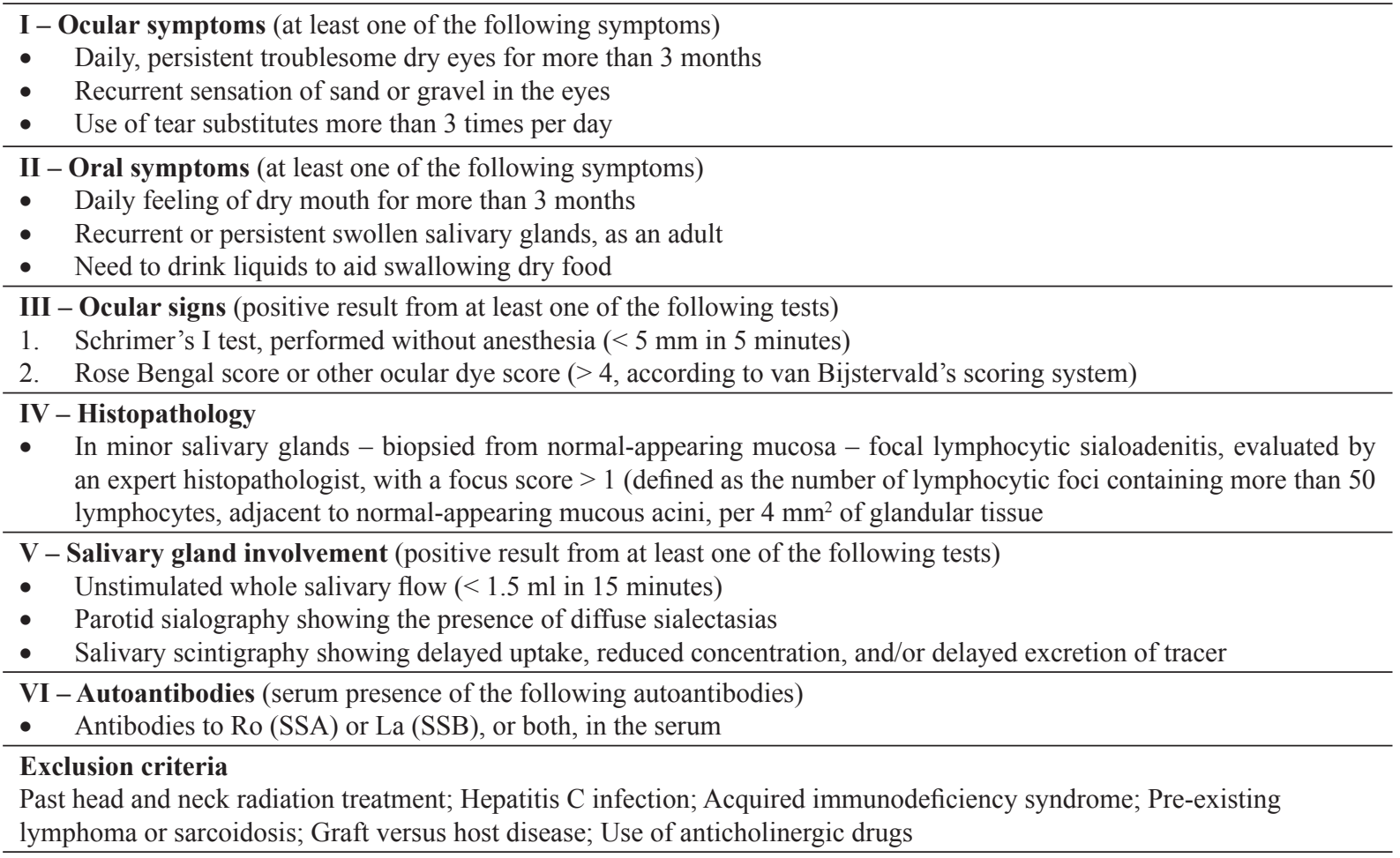

Table 2. Revised Japanese Criteria for Sjögren's Syndrome, 1999

I - Histopathology (positive for at least one of the following)

- Focus score $\geq 1$ (periductal lymphoid cell infiltration $\geq 50$ ) in a $4 \mathrm{~mm}^{2}$ minor salivary gland biopsy

- $\quad$ Focus score $\geq 1$ (periductal lymphoid cell infiltration $\geq 50$ ) in a $4 \mathrm{~mm}^{2}$ lacrimal gland biopsy

II - Oral Examination (positive for at least one of the following)

- Abnormal findings in sialography $\geq$ Stage I (diffuse punctate shadows of less than $1 \mathrm{~mm}$ )

- Decreased salivary secretion (flow rate $\leq 10 \mathrm{ml} / 10 \mathrm{~min}$ according to the chewing gum test or $\leq 2 \mathrm{~g} / 2 \mathrm{~min}$ according to the Saxon test) and decreased salivary function according to salivary gland scintigraphy

III - Ocular Examination (positive for at least one of the following)

- Schirmer's test $\leq 5 \mathrm{~mm} / 5 \mathrm{~min}$ and Rose Bengal test $\geq 3$ according to the van Bijsterveld score

- Schirmer's test $\leq 5 \mathrm{~mm} / 5 \mathrm{~min}$ and positive fluorescein staining test

IV - Serological Examination (positive for at least one of the following)

- Anti-Ro/SS-A antibody

- Anti-La/SS-B antibody

for the SS criteria, are based on a subjective analysis difficult to translate into quantifiable data. Nonetheless, it is routinely found that specific groups of patients (for instance, children and adolescents, or individuals experiencing chronic discomfort and distress) quite often deny having symptoms, nevertheless objective tests for dysfunction of the assayed exocrine glands (item II and III) give abnormal results [7]. This might be related to the fact that these individuals accept discomfort as a normal condition - as most may have felt it for most of their lives - and curtail its diagnostic relevance.

The authors converge into a position more close to the one of the Japanese expert group, stating that the symptomatology should not be included into the classification criteria for SS diagnosis, but should be highly regarded in the complex treatment of SS.

\section{Ocular testing}

The Schirmer test for the eye quantitatively measures tear formation via placement of filter paper in the lower conjunctival sac []ㅡ. Standardized paper strips (with $5 \mathrm{~mm}$ width and $35 \mathrm{~mm}$ length) should be used and placed in the lower eyelids. Schirmer test without anaesthesia or Schirmer I (STI), is a well-standardized test that measures the basal tear secretion with the conjunctival-lachrymal trigeminal reflex, while the procedure of the Basal Schirmer test (STB) is performed with anaesthesia and measures the basal 
lachrymal secretion [9]. Other variations of the Schirmer test are less frequently used in SS diagnosis.

In STI, the strip is placed in the lower fornix between the medial and lateral third of the eyelid of the unanaesthetised eye. After 5 minutes, the amount of wetting is measured from the extrafornical position of the strip [10]. According to both the Revised International Classification Criteria for Sjögren's syndrome and the Japanese criteria, if less than $5 \mathrm{~mm}$ of paper are wetted following 5 minutes of the STI test, the result of the test is considered positive. In Figure 1, the STI test and its results, conducted on a SS-affected individual, are shown.

Alternatively, positive ocular surface Rose Bengal or other ocular dye score, (i.e., fluorescein vital staining, lissamine green, etc.) can also be conducted. These tests are most commonly used for the evaluation of ocular surface epithelial damage, since these vital stains mark cells, on the surface of the eye, that are not fully coated by the mucin layer of tear fluid and/ or are damaged. The Rose Bengal score, a quantified version of the original Rose Bengal test, is commonly used to quantify the degree of staining $[\underline{8}, \underline{11}]$. The test is conducted by the application of a $1 \%$ solution of Rose Bengal, within the inferior fornix of both eyes. The patient should be following asked to make one or two full blinks. The examiner uses white light to assess the amount of staining, in the two exposed conjunctival zones (medial and lateral) and cornea. Each section is scored up to 3 points, according to the Van Bijsterveld score: 1, sparsely scattered spots; 2, densely scattered spots; and 3, confluent spots). While the maximum score is 9 , a score of 4 or more, or 3 or more, was considered diagnostic of SS, according to the International classification criteria, or Japanese criteria for SS, respectively. In patients with SS, Rose Bengal staining can cause the eyes to sting and the test may be painful. Scoring with lissamine green stain is less painful, but more difficult to evaluate.

The tear break up time (BUT) test aims to measure the quality of the tear fluid [8]. It is defined as the interval between a complete blink and the appearance of the first randomly distributed dry spots. Usually, a 1\% fluorescein solution is carefully placed in the inferior fornix of both eyes. The patient is then asked to blink a few times, and then, it is examined how long the tear film remains evenly distributed over the surface of the cornea [11]. The tear film normally remains intact for 10 seconds or longer, being highly abnormal in SSaffected individuals.

Laser scanning confocal microscopy (LSCM) has been recently used as an efficient, noninvasive, in vivo and fast tool to quantitative assess the conjunctival inflammation and epithelial cell densities, as well as the evaluation of conjunctival morphologic alterations in patients with SS [12]. Furthermore, LSCM may be a valuable tool in monitoring the progress and the follow-up of patients with Sjögren's syndrome dry eye [13].

According to the reported criteria for SS diagnosis, the Revised International Classification Criteria substantiates that of the various tests that can be performed, only one single abnormal result is sufficient for the objective evidence of lachrymal gland involvement. On the contrary, the Japanese expert group agreed on that at least two objective tests for determining lachrymal gland involvement should be conducted and report abnormal results. While the authors converge to the need of test validation, and thus the requirement of at least two abnormal test results to claim the affection of lachrymal glands, it is clear that the STI test has the great advantage that can be easily conducted within the dental office while other ocular tests require the assistance of a certified ophthalmologist.

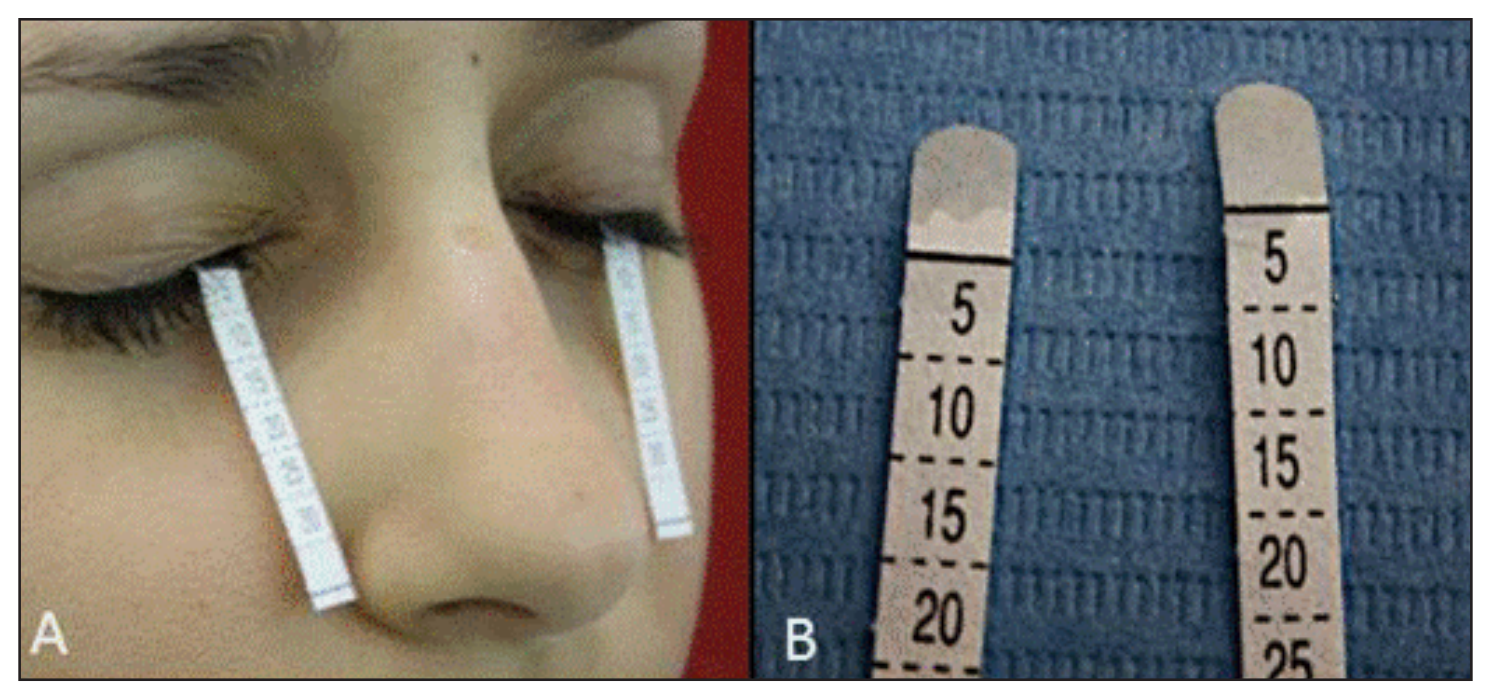

Figure 1. STI test (A) and test results (B) revealing a significant reduction in lachrymal secretion. 


\section{Histopathological analysis}

Minor salivary gland biopsy remains a highly used diagnostic procedure for the salivary component of SS. This is usually performed on the internal face of the lower lip on normal-appearing mucosa. Under local anaesthesia an incision of around 1.5 to $2 \mathrm{~cm}$ is made between midline and the commissure, through the mucosa with penetration of the epithelium. With this procedure, usually 5 or more minor salivary glands are excised. The biopsy contributes towards the diagnosis of SS if the histopathological examination reveals a mononuclear infiltration with periductal or perivascular distribution. The inflammatory infiltrate is quantified and a cluster of $\geq 50$ lymphocytes is termed a focus. The numbers of focus in an area of $4 \mathrm{~mm}^{2}$ of tissue surface render the focus score. A focus score $\geq 1$, as according to both the Revised International Classification Criteria and the Japanese expert criteria, are considered positive for SS diagnosis.

As an example, salivary gland tissue from a patient with Sjögren's syndrome, with a focus score greater than 4, is shown in Figure 2.

Minor salivary gland lip biopsy results, nonetheless reporting a useful diagnostic value in SS, should be carefully addressed in the overall diagnostic procedure due to inconsistencies of sensitivity and specificity. A false negative result range from around 20 to $40 \%$ and also positive biopsy results have been found up to $10 \%$ of healthy individuals [14]. In one study, abnormal biopsies (with a focus score ranging from 2 to 6 ) have been found in $15 \%$ of healthy volunteers with no subjective xerostomia or dry eyes [15]. Also, patients affected by myasthenia gravis, sialolithiasis and other autoimmune disorders not associated with sicca symptoms may also reveal minor salivary gland infiltration [16]. Other factors can also affect focus score determination; cigarette smoking is negatively associated with sialadenitis focus score $>1$, in patients with primary Sjögren's syndrome [17]. Lip biopsies analysis has also been found to induce a poor interrater reliability in histopathological analysis, in terms of diagnostic status, focus scores and histological characteristics [18]. The extents of infiltrates in a lip biopsy using the same methodological approach may vary greatly from gland to gland in a single patient. Further, if the density of infiltrate is severe, the foci may become confluent, hindering focus score determination. These and other factors may converge to justify that, in one study, a second evaluation of the histopathological analysis of labial salivary glands biopsies significantly changed the initial diagnosis in 32 of 60 studied cases (53\%) [19].

In a different approach, and apart from the diagnostic

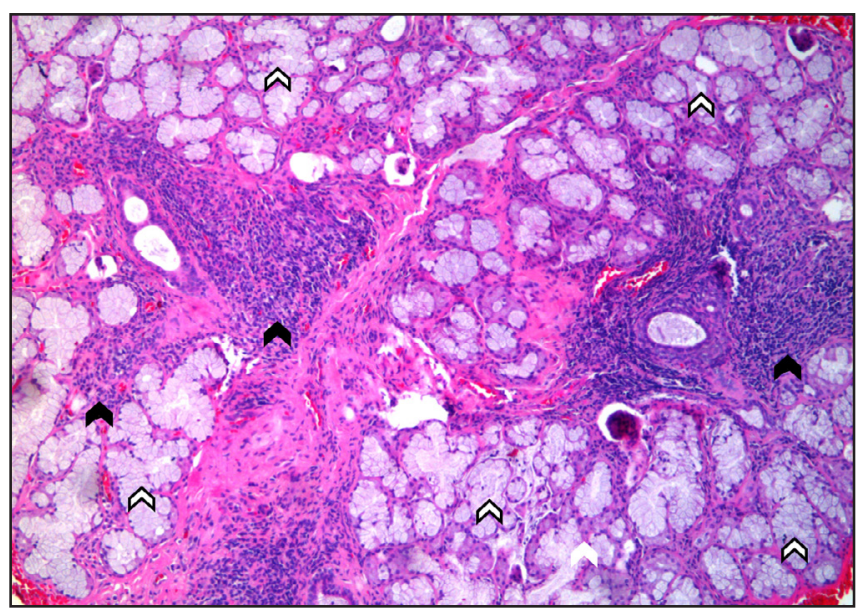

Figure 2. Labial salivary gland biopsy consistent with Sjögren's syndrome, showing multiple lymphocytic foci (black arrow) and intact acinar units (white arrow) (hematoxylin and eosin stain, original magnification $\mathrm{x} 100)$.

value, the performance of lymphoid organization in the form of germinal centre-like lesions in labial salivary gland biopsies, taken at SS diagnosis, was proposed as a highly predictive marker for non-Hodgkin's lymphoma development - associated with a high risk of mortality in pSS-affected individuals [20].

Alternative biopsy techniques have also been proposed on the assessment of pSS diagnosis. In one study, parotid biopsy was shown to have a diagnostic potential comparable with that of a labial biopsy and could further be associated with less morbidity [21]. Additionally, in a case report where the patient revealed ocular and oral symptoms and signs, but did not meet the SS classification criteria according to the Revised International Classification Criteria (no anti-SSA or anti-SSB antibodies were detected, and minor salivary gland biopsy was normal), parotid gland biopsy was a supplementary diagnostic tool to support the SS diagnosis [22].

\section{Salivary glands testing Sialometry}

Sialometry aims to measure the saliva flow function, and can be conducted with whole saliva, saliva obtained from a specific gland, both with or without stimulation. Whole saliva tests are generally easier and more conveniently performed. For a diagnosis of hyposalivation, the unstimulated whole saliva flow rate (UWSFR) has been proposed as the test of choice, as it may be reduced, even if the stimulated whole saliva is unaffected [23]. Unstimulated collection is conducted by the recovery of saliva in a grading tube by a predetermined period usually 5 or 15 minutes. Values inferior to $0.1 \mathrm{~mL} / \mathrm{min}$ are considered abnormal [24]. This test quantifies saliva secretion from all salivary glands and is believed to 
show alterations at the early stages of the disease, being highly reproducible [25]. According to the Revised International Classification Criteria, the unstimulated whole saliva produced over a period of 15 minutes, without the subjects have eaten or smoked for at least 2 hours, should be measured. A result inferior to $1.5 \mathrm{ml}$ would transpose to a positive test result. Many researchers, including the authors, consider the testing time excessively long, with alternative techniques considering shorter periods being equally validated $[\underline{26}, 27]$. This comes in line with the Japanese criteria which rely on the assessment of stimulated whole saliva tests as they shows less examiner associated bias.

Stimulated saliva assessment can be complicated in patients who do not tolerate the stimulus of salivation and, moreover, due to the wide variety of used stimulus (i.e., citric acid, gum, paraffin etc.) there is a generalized lack of agreement for normal values. A flow rate inferior to $10 \mathrm{ml} / 10$ minutes, in the chewing gum test, is considered positive in the Japanese criteria. Alternatively, these criteria refer to the Saxon test, in which a $10 \times 10$ gauze sponge should be weighted and used for saliva collection by vigorous chewing for 2 minutes. The amount of saliva produced is determined by subtracting the original weight from the weight obtained after chewing. In the Japanese criteria, a value inferior to $2 \mathrm{~g} / 2$ minutes is considered positive.

Collection of the stimulated parotid saliva, and subsequent assessment of the flow rate, can be conducted with the requirement of special suction cups placed over the Stensen duct. Stimulated saliva is usually collected for 3 minutes and values inferior to $0.5 \mathrm{~mL} / \mathrm{min}$ are considered abnormal [24]. Despite the high sensitivity, the stimulated parotid saliva sialometry may fail to reveal alterations at the initial stages of the disease, requires special equipment and may not be easily tolerated by patients [28].

The lower lip mucosa is dried for 5 min expecting the small saliva drops to occur. The width of the drop less than $1 \mathrm{~mm}$ is considered to show hipofunction. This test is easy to perform, but still needs more investigation to be included in SS classification criteria instead of lower lip biopsy [르].

Several authors also highlight to the variation found in sensitivity and specificity (ranging from around 45 to $82 \%$, and from 60 to $92 \%$, respectively) of sialometry in SS diagnosis [14]. In fact, salivary secretion is dependent on many factors including time of the day, circadian rhythm, degree of hydratation, body position, smoking, sex, age, body mass, exposure to light and multiple medications [30]. This is also clear that there might be no obvious correlations of oral dryness with the measurements of saliva function. Critical salivation level to occur dryness is dependent upon person and may be related to relative diminishion of saliva above $50 \%$.

Nonetheless, it is the authors' inkling that salivary flow should be routinely performed, not only as part of SS diagnosis, but also as part of patient monitoring.

\section{Sialography}

This study requires the radiographic imaging of a salivary gland (usually the parotid), following the retrograde injection of a contrast medium through the excretory duct. The medium is distributed through the duct system, allowing the analysis of the architecture and configuration of the glandular ducts' organization. In SS-affected patients it can be verified a dilatation and twisting of the ducts, with an uneven distribution of the contrast medium, broadly originating the appearance of a branching pattern of the ducts. A positive result in the sialographic study is part of both the Revised International Classification criteria and Japanese criteria for the SS diagnosis.

Sialography may be technically challenging, timeconsuming, painful and risky. In fact it is contraindicated in severe gland dysfunction due to the risk of indefinitely retaining the contrast medium $[\underline{31}, \underline{32}]$. Sialography has been shown to have a high accuracy in the diagnosis of SS, nonetheless sialectasis may also be found in healthy individuals, as well as in individuals affected by other diseases like chronic sialadenitis [14]. Also, several reports showed that that the diagnostic value of parotid sialography for diagnosing SS greatly depends on the skills of the observer [33]. Nonetheless, given the potentially high sensitivity and specificity in SS diagnosing, as well as its useful staging potential, sialography still has its use in the evaluation of the oral component of SS. Diagnosis is generally based on the classification of Rubin and Holt [34] in which stage 0 (normal) corresponds to no contrast media collection; stage 1 (punctate) refers to contrast media collection $\leq 1 \mathrm{~mm}$ in diameter; stage 2 (globular) refers to contrast media collection between 1 and $2 \mathrm{~mm}$ in diameter; stage 3 (cavitary) refers to contrast media collection $\geq 2 \mathrm{~mm}$ in diameter; and stage 4 (destructive) refers to the complete destruction of the gland parenchyma.

A sialography of a SS-affected patient (Stage 3) 5 minutes following the injection of the contrast medium is reported in Figure 3.

\section{Scintigraphy}

The scintigraphy is a non-invasive method to evaluate the function of salivary glands by addressing the uptake and secretion of a radioactive labelled substance (sodium pertechnate of ${ }^{99 \mathrm{~m}} \mathrm{Tc}$ ). Additionally, 


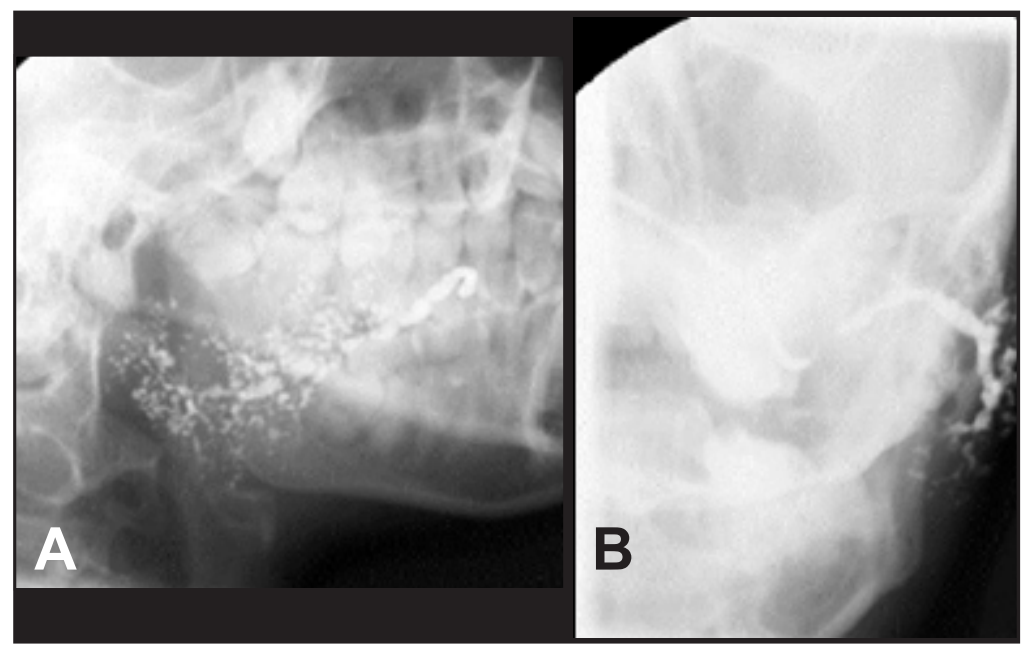

Figure 3. Sialographic imaging of the parotid gland (Stage 3, according the Rubin and Holt classification). $\mathrm{A}=$ frontal view; $\mathrm{B}=$ lateral view. Note the dilated main duct and the sparse overall branching pattern of the ducts.

an abnormal salivary gland scintigraphy result is accepted by the American - European consensus group as a criterion for the diagnosis of Sjögren's syndrome. Normally, a rapid uptake and increased concentration of the radioactive probe is attained in the salivary glands (it can normally be seen within 10 minutes following intravenous administration). After 20 - 30 minutes, the substance is rapidly secreted into the mouth. Salivary flow may be stimulated with the use of a sialogogue (e.g., diluted lemon juice) administered to the dorsal tongue. Time-activity curves are calculated using manually drawn oval regions-of-interest around both the parotid and the submandibular glands. In Sjögren's syndrome, lower concentration and less secretion into the mouth are seen. The test reports a high sensitivity but a low specificity in SS diagnosis.

Scintigraphy data results are expressed as quantitative values, which are transformed to semi qualitative indices. But generally in practice qualitative and observer-dependent classification is used to present the results and to search for clinical correlations. Schall's categorical classification is usually considered the standard method for salivary scintigraphy interpretation, though subjective and with limited capacity to discriminate borderline results [35]. In this classification system, the uptake and discharge of the radioactive probe is visually evaluated, and the glands are individually graded from 1 (normal) to 4 (severe affection) [36]. Accordingly, several quantifiable indices of salivary function have been proposed including the rate of trapping and uptake, time of maximum activity, uptake ratios and magnitude or rate of stimulated salivary discharge [35]. Nonetheless, few studies evaluated the centrality and dispersion of these quantitative scintigraphic indices in wellcharacterized groups of controls, and the validity and acceptance of such criteria still remain to be established. In which relates to SS, a recent report has shown a correlation between the severity of the scintigraphic involvement and a more pronounced autoimmune involvement with an increased risk to develop systemic features, lymphoma, and a lower survival rate [37]. Other reports also substantiate the relevance of scintigraphy in the assessment of glandular dysfunction and of the disease severity $[38,39]$. The authors corroborate the relevance of the scintigraphic study at SS diagnosis, due to the valuable clinical information on the prognosis and outcome of both pSS and sSS.

However, this technique needs special equipment and staff that can only be found in reference clinical centers. Further, it may be unacceptable for the patient due to risk of radiation damage and high cost.

A scintigraphic study of the salivary glands of an SSaffected patient is shown in Figure 4.

\section{Magnetic Resonance (MR) and ultrasonography (US)}

MR imaging (MRI), MR sialography and US are noninvasive methodologies that allow the imaging of salivary glands in their physiological state without artefacts induced by intraductal contrast media or biopsy procedures. Further, these imaging modalities allow a reduction in the inconveniences and risk of complications to the patient [40]. Recent advances in technical equipment allowed for the yield of such a definitive picture of the glandular structural changes that they are promising alternatives to conventional examinations.

MR imaging was shown to provide a reliable imaging procedure to evaluate glandular alterations. It allows multiplanar evaluation and processes a high contrast tissue resolution. Characteristically, in SS, MRI reveals an inhomogeneous internal pattern on both $\mathrm{T} 1$ and T2 sequences, with multiple hypo- and hyper-intense nodules of different sizes [40]. MRI quantitative analysis for the standard deviation of the signal intensity was found to be useful in SS diagnosis. The signal intensity in T1-weighth parotid MR images was found to increase proportionally to the severity of the disease [41]. Further, other MR modalities in the SS assessment have been used, including MR sialography, functional MR sialography, and dynamic contrast-enhanced MRI. The latter and tracer kinetic modelling were used to quantify the altered microvascular pathophysiologic features of salivary glands in SS [42]. SS-affected patients were shown to report a great differentiation and 


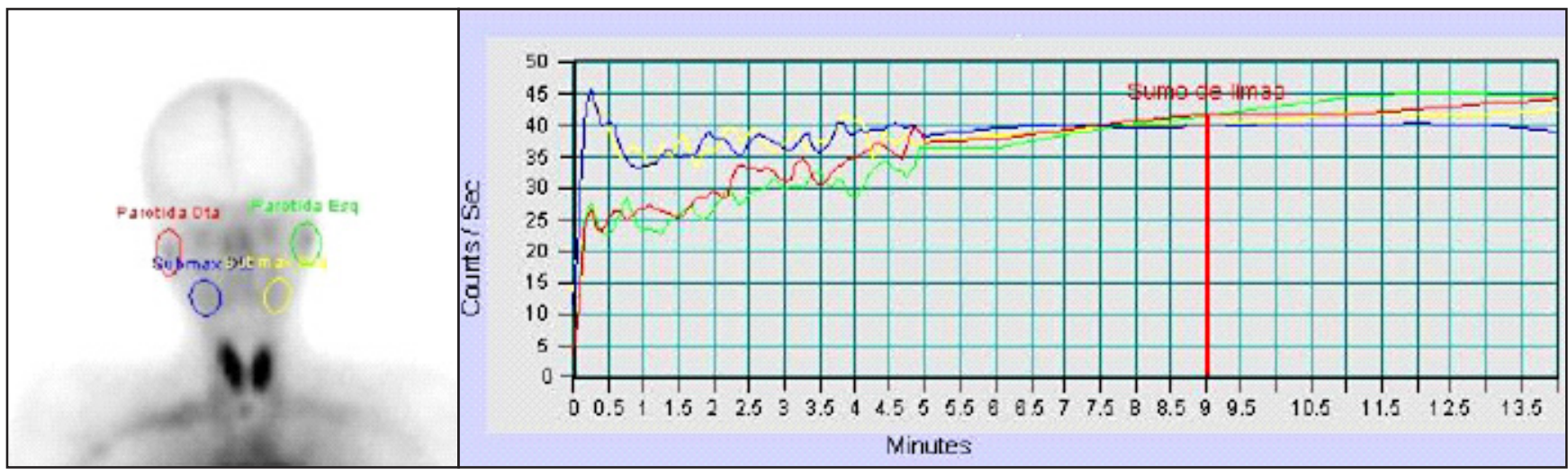

Figure 4. Scintigraphic study of the salivary glands (class IV, according to the Schall's classification). The right parotid gland is encircled in red, the left parotid gland is encircled in green, the right submandibular gland is encircled in blue and the left submandibular gland is encircled in yellow. Time-activity curves are presented on the right and each colour corresponds to the previously encircled glands, respectively. Note the severe functional affection with a significant reduction in the uptake of the radioactive probe and absence of the discharge phase, even after the stimulation with a sialogogue (red line at 9 minutes).

an increased heterogeneity in microvascular parameters, comparing to controls [42].

MR sialography has largely replaced conventional sialography in the latter years and can produce sialographic images similar to those of conventional sialography without the use of contrast media or radiation. The underlying principles are set on the use of a protocol that uses a heavily T2-weighted, fat-suppressed pulse sequence and rapid acquisition with relaxation enhancement [43]. It has been found to be highly accurate and sensitive in the evaluation of salivary gland disease in SS [44]. Furthermore, dynamic MR sialographic images and data were also shown to be useful in the diagnosis of patients with SS. Significant reduced values have been found regarding the maximum area and the ratio of change in the detectable ducts, in SS-affected patients, comparing to control $[\underline{45}, \underline{46}]$.

Salivary ultrasonography (US) is a noninvasive and low cost imaging technique that has been recently used in the diagnosis and staging of SS. US is more effective on the parotid gland and less helpful in the assessment of other salivary glands. Moreover, it is a technique highly operator-dependent [47]. Despite these characteristics, US detection of parenchymal inhomogenicity of the major salivary glands and observation of reduced volume of the submandibular glands resulted in high specificities for diagnosis of pSS and sSS [48]. Characteristic US features of SS include an inhomogeneous structure of the gland (early stages), with scattered multiple small, oval, hypoechoic or anechoic areas of lymphocytic infiltrates (intermediate stages), and the presence of echogenic lines - fibrosis - that converge into a glandular reticular pattern (late stages) usually well defined. Other features, though more uncommonly found, may include the dilatation of the main duct, increased parenchymal blood flow (accessed by Doppler), pseudo masses, irregular cystic masses, and intraparotid lymph node enlargement [48]. Recent reports converge to the relevance of the diagnostic value of US and substantiate its use over more invasive methodological approaches [49, 50].

An US of the parotid and submandibular glands is shown in Figure 5.

The authors come together to the relevance of the available noninvasive imaging modalities in the assessment of salivary gland involvement in SS, despite the acknowledgement that comparative largescale multicenter studies should be conducted to confirm the relation between diagnostic value and costeffectiveness in SS.

\section{Sialochemistry}

Sialochemistry involves the analysis of salivary composition, both including organic and inorganic constituents, by means of different biochemical, electrophoretic and immunological analytical methods. They aim to address the injuries submitted to salivary glands regarding secretion content. Various parameters have been evaluated and the salivary protein profile of SS is a mixture of increased inflammatory proteins and decreased acinar proteins when compared to healthy controls [51,52]. Moreover, proteomic approaches have also been conducted on the saliva of SS patients. Differences regarding protein expression were found between SS patients and healthy subjects. However, individual analysis of SS patients exhibited distinct patterns of protein expression and did not correlate with the clinical, serological or histological severity of disease [53-55]. Also ionic changes were observed in SS-affected individuals, namely regarding the levels of chloride, potassium, calcium, sodium and magnesium $[\underline{28}, \underline{56}]$. Despite attained variations, sialochemistry is considered nondiscriminatory and of no diagnostic 


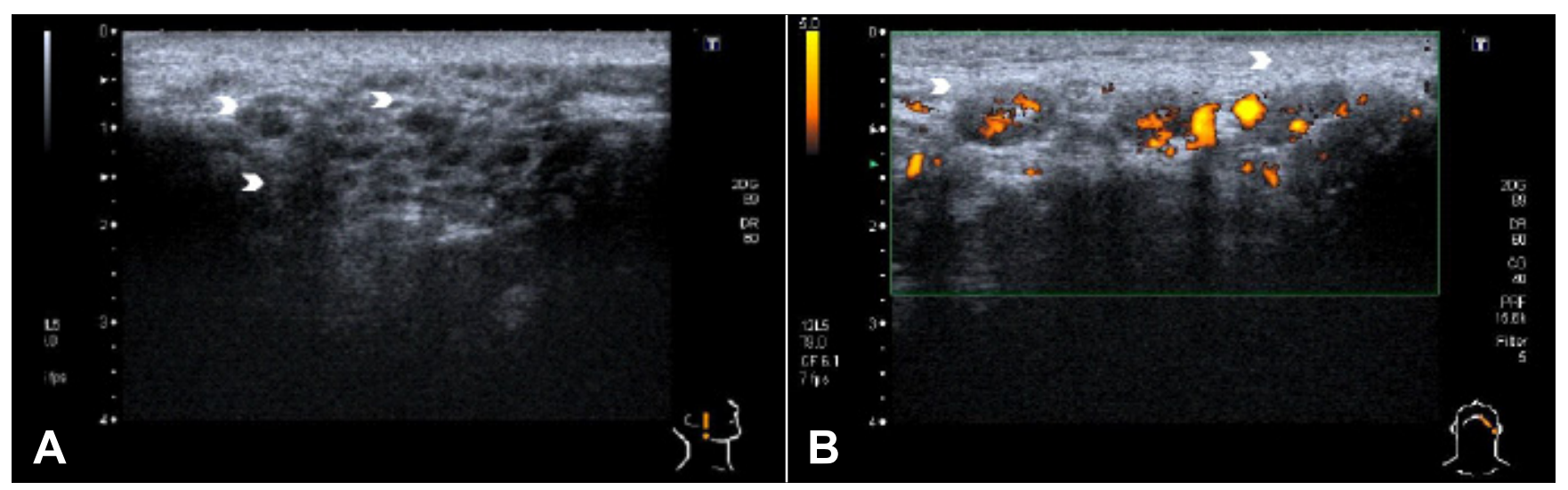

Figure 5. Gray-scale (A) and a power Doppler (B) US images showing advanced-stage Sjögren's syndrome in salivary glands. The gland has an inhomogeneous structure with multiple small, oval, hypoechoic areas (arrowheads) and increased blood flow. The position of the US probe is shown in the inset diagram. A = imaging of the right parotid gland; $\mathrm{B}=$ imaging of the left submandibular gland.

relevance due to the attained inter-individual variation in both SS-affected patients and healthy controls, lack of standardization in saliva collection and regarding analytical procedures. Furthermore, some SS patients produce little or no saliva which limits sialochemistry applications.

\section{Plasmatic and serologic markers}

Patients affected by SS usually present a wide range of serologic and laboratory findings, ranging from cytopenias (e.g., anaemia, leukopenia, thrombocytopenia), hypergammaglobulinemias (usually of the $\operatorname{IgG}$ class, and more rarely of the $\operatorname{IgA}$ and IgM classes), high erythrocyte sedimentation rate and C-protein levels, and autoantibodies $[57, \underline{58]}$. Of the latter, antinuclear antibodies (ANAs) is the most frequently detected, while anti-Ro/SS-A is the most specific (despite occurring in other autoimmune disorders), and cryoglobulins and hypocomplementemia is the main prognostic markers [ㄷ].

Positive autoantibodies are one the attained classification criteria for SS in both the Revised International Classification and the Japanese Revised criteria, being the only analytical data included. The 1993 European Criteria include the presence of one or more of ANAs, rheumatoid factor (RF), Ro/SS-A, and/or La/SS-B, while the 2002 Criteria include only anti-Ro/SS-A and/or anti-La/SS-B antibodies. ANAs are the most frequently detected auto-antibodies in pSS and are closely associated with various extraglandular and analytical SS features [60], as RF, which is broadly associated with the main extraglandular, histopathologic, haematologic, and immunologic SS feature $[61,62]$. In fact ANAs and RF have shown to possess predictive and prognostic values for those patients who do not fulfil the higher stringent 2002 revised criteria but are indicated for immunomodulatory therapy [61]. The authors substantiate that ANA and RF determinations may play a central role in diagnosis of SS, especially in those patients with suspected evidences but failing to fulfil the classification criteria.

Despite the relevance of ANAs and RF, the most widely used biomarkers of SS are still serum IgG autoantibodies against two nuclear proteins, Ro-52/SSA and La/SSB. In clinical setting, these antibodies are measured in serum for diagnostic purpose. IgG anti-La/SSB antibodies represent the major serum antibody class, whereas $\operatorname{Ig} \mathrm{A}$ and IgM are rarely detected. IgG antibodies, rarely IgA, are also detected in saliva from patients with SS. As for anti-Ro/SSA, IgG remains to be the main class while IgA and IgM classes have not been identified [63]. Some other autoantibodies, including anti- $\alpha$-fodrin antibody, anti-type 3 muscarinic acetylcholine receptor and anticentromere antibodies were also found to be associated with pSS [64-66]. Nonetheless, their specificity and sensitivity is inferior to classic assessed markers (Ro52/SSA and $\mathrm{La} / \mathrm{SSB}$ ).

Several studies have also found that patient with hypocomplementemia and cryoglobulins at diagnosis were shown to possess a higher risk of developing vasculitis and B-cell lymphoma during follow-up, and that the presence of these markers reported to be a key prognostic value in patient survival $[67,68]$. Verified hypocomplementemia may be due to the complement activation caused by cryoglobulinemia.

\section{CONCLUSIONS}

Sjögren's syndrome is a common autoimmune disease of which the diagnosis and treatment are frequently delayed. Due to its systemic involvement, it can exhibit a wide range of clinical manifestations that contribute to confusion and delay in diagnosis. An increased awareness of SS and its many and varied manifestations encourages a more expansive approach to diagnosing this disease. The use of recently refined criteria for 
diagnosis can assist in identifying patients with SS early. Particularly, due to the fact that there is no simple and validated test for SS diagnosis and the need for an easy, low-cost and straightforward test for the assessment of the oral component of SS, is still highly demanded.The use of all available diagnostic modalities will help to reduce the time to diagnosis and preserve the health and

\section{ACKNOWLEDGMENTS AND DISCLOSURE STATEMENTS}

The authors declare that they have no conflict of interests. quality of life of patients with SS.

\section{REFERENCES}

1. Fox RI. Sjögren's syndrome. Lancet. 2005 Jul 23-29;366(9482):321-31. Review. [Medline: 16039337] [doi: 10.1016/S0140-6736(05)66990-5]

2. Vitali C, Bombardieri S, Moutsopoulos HM, Balestrieri G, Bencivelli W, Bernstein RM, Bjerrum KB, Braga S, Coll J, de Vita S, et al. Preliminary criteria for the classification of Sjögren's syndrome. Results of a prospective concerted action supported by the European Community. Arthritis Rheum. 1993 Mar;36(3):340-7. [Medline: 8452579] [doi: 10.1002/art.1780360309]

3. Vitali C, Bombardieri S, Jonsson R, Moutsopoulos HM, Alexander EL, Carsons SE, Daniels TE, Fox PC, Fox RI, Kassan SS, Pillemer SR, Talal N, Weisman MH; European Study Group on Classification Criteria for Sjögren's Syndrome. Classification criteria for Sjögren's syndrome: a revised version of the European criteria proposed by the American-European Consensus Group. Ann Rheum Dis. 2002 Jun;61(6):554-8. Review. [Medline: 12006334] [doi: 10.1136/ard.61.6.554] [FREE Full Text]

4. Baldini C, Talarico R, Tzioufas AG, Bombardieri S. Classification criteria for Sjogren's syndrome: A critical review. J Autoimmun. 2011 Dec 30. [Epub ahead of print] [Medline: 22209352] [doi: 10.1016/j.jaut.2011.12.006]

5. Fujibayashi T, Sugai S, Miyasaka N, Toujou T, Miyawaki M, Ichikawa Y. Revised Japanese Creteria for Sjögren's syndrome. Tokyo 1999. p. 135-9.

6. Fujibayashi T, Sugai S, Miyasaka N, Hayashi Y, Tsubota K. Revised Japanese criteria for Sjögren's syndrome (1999): availability and validity. Mod Rheumatol. 2004 Dec;14(6):425-34. [doi: 10.1007/s10165-004-0338-x]

7. Bartůnková J, Sedivá A, Vencovský J, Tesar V. Primary Sjögren’s syndrome in children and adolescents: proposal for diagnostic criteria. Clin Exp Rheumatol. 1999 May-Jun;17(3):381-6. [Medline: 10410277]

8. Paschides CA, Kitsios G, Karakostas KX, Psillas C, Moutsopoulos HM. Evaluation of tear break-up time, Schirmer's-I test and rose bengal staining as confirmatory tests for keratoconjunctivitis sicca. Clin Exp Rheumatol. 1989 MarApr;7(2):155-7. [Medline: 2736828]

9. Cho P, Yap M. Schirmer test. I. A review. Optom Vis Sci. 1993 Feb;70(2):152-6. Review. [Medline: $\underline{8446379]}$ [doi: 10.1097/00006324-199302000-00011]

10. Cho P, Yap M. Schirmer test. II. A clinical study of its repeatability. Optom Vis Sci. 1993 Feb;70(2):157-9. [Medline: 8446380] [doi: 10.1097/00006324-199302000-00012]

11. Vitali C, Moutsopoulos HM, Bombardieri S. The European Community Study Group on diagnostic criteria for Sjögren's syndrome. Sensitivity and specificity of tests for ocular and oral involvement in Sjögren's syndrome. Ann Rheum Dis. 1994 Oct;53(10):637-47. [Medline: 7979575] [doi: 10.1136/ard.53.10.637] [FREE Full Text]

12. Wakamatsu TH, Sato EA, Matsumoto Y, Ibrahim OM, Dogru M, Kaido M, Ishida R, Tsubota K. Conjunctival in vivo confocal scanning laser microscopy in patients with Sjögren syndrome. Invest Ophthalmol Vis Sci. 2010 Jan;51(1):14450. Epub 2009 Aug 20. [Medline: 19696170] [doi: 10.1167/iovs.08-2722] [FREE Full Text]

13. Hong J, Zhu W, Zhuang H, Xu J, Sun X, Le Q, Li G, Wang Y. In vivo confocal microscopy of conjunctival goblet cells in patients with Sjogren's syndrome dry eye. Br J Ophthalmol. 2010 Nov;94(11):1454-8. Epub 2009 Dec 2. [Medline: 19955202] [doi: 10.1136/bjo.2009.161059]

14. Soto-Rojas AE, Kraus A. The oral side of Sjögren syndrome. Diagnosis and treatment. A review. Arch Med Res. 2002 Mar-Apr;33(2):95-106. Review. [Medline: 11886706] [doi: 10.1016/S0188-4409(01)00371-X]

15. Radfar L, Kleiner DE, Fox PC, Pillemer SR. Prevalence and clinical significance of lymphocytic foci in minor salivary glands of healthy volunteers. Arthritis Rheum. 2002 Oct 15;47(5):520-4. [Medline: 12382301] [doi: 10.1002/art.10668] [FREE Full Text]

16. Vitali C, Tavoni A, Simi U, Marchetti G, Vigorito P, d'Ascanio A, Neri R, Cristofani R, Bombardieri S. Parotid sialography and minor salivary gland biopsy in the diagnosis of Sjögren's syndrome. A comparative study of 84 patients. J Rheumatol. 1988 Feb;15(2):262-7. [Medline: 3258917]

17. Manthorpe R, Benoni C, Jacobsson L, Kirtava Z, Larsson A, Liedholm R, Nyhagen C, Tabery H, Theander E. Lower frequency of focal lip sialadenitis (focus score) in smoking patients. Can tobacco diminish the salivary gland involvement as judged by histological examination and anti-SSA/Ro and anti-SSB/La antibodies in Sjögren's syndrome? Ann Rheum Dis. 2000 Jan;59(1):54-60. [Medline: 10627428] [doi: 10.1136/ard.59.1.54] [FREE Full Text] 
18. Stewart CM, Bhattacharyya I, Berg K, Cohen DM, Orlando C, Drew P, Islam NM, Ojha J, Reeves W. Labial salivary gland biopsies in Sjögren's syndrome: still the gold standard? Oral Surg Oral Med Oral Pathol Oral Radiol Endod. 2008 Sep;106(3):392-402. Epub 2008 Jul 7. [Medline: 18602295] [doi: 10.1016/j.tripleo.2008.04.018]

19. Vivino FB, Gala I, Hermann GA. Change in final diagnosis on second evaluation of labial minor salivary gland biopsies. J Rheumatol. 2002 May;29(5):938-44. [Medline: 12022353]

20. Theander E, Vasaitis L, Baecklund E, Nordmark G, Warfvinge G, Liedholm R, Brokstad K, Jonsson R, Jonsson MV. Lymphoid organisation in labial salivary gland biopsies is a possible predictor for the development of malignant lymphoma in primary Sjögren's syndrome. Ann Rheum Dis. 2011 Aug;70(8):1363-8. [Medline: 21715359] [doi: 10.1136/ard.2010.144782] [FREE Full Text]

21. Pijpe J, Kalk WW, van der Wal JE, Vissink A, Kluin PM, Roodenburg JL, Bootsma H, Kallenberg CG, Spijkervet FK. Parotid gland biopsy compared with labial biopsy in the diagnosis of patients with primary Sjogren's syndrome. Rheumatology (Oxford). 2007 Feb;46(2):335-41. Epub 2006 Aug 5. [Medline: 16891656] [doi: 10.1093/rheumatology/kel266] [FREE Full Text]

22. Soyfoo MS, Catteau X, Delporte C. Parotid Gland Biopsy as an Additional Diagnostic Tool for Supporting the Diagnosis of Sjögren's Syndrome. Int J Rheumatol. 2011;2011:302527. Epub 2011 Aug 7. [Medline: 21845192] [doi: 10.1155/2011/302527] [FREE Full Text]

23. Sreebny LM. Salivary flow in health and disease. Compend Suppl. 1989;(13):S461-9. Review. [Medline: 2691080]

24. Atkinson JC. The role of salivary measurements in the diagnosis of salivary autoimmune diseases. Ann N Y Acad Sci. 1993 Sep 20;694:238-51. Review. [Medline: 8215059] [doi: 10.1111/j.1749-6632.1993.tb18357.x]

25. Sreebny L, Zhu WX. Whole saliva and the diagnosis of Sjögren's syndrome: an evaluation of patients who complain of dry mouth and dry eyes. Part 1: Screening tests. Gerodontology. 1996 Jul;13(1):35-43. [Medline: 9452640] [doi: 10.1111/j.1741-2358.1996.tb00148.x]

26. Gotoh S, Watanabe Y, Fujibayashi T. Validity of stimulated whole saliva collection as a sialometric evaluation for diagnosing Sjögren's syndrome. Oral Surg Oral Med Oral Pathol Oral Radiol Endod. 2005 Mar;99(3):299-302. [Medline: 15716835] [doi: 10.1016/i.tripleo.2004.09.016]

27. López-Jornet P, Camacho-Alonso F, Bermejo-Fenoll A. A simple test for salivary gland hypofunction using Oral Schirmer's test. J Oral Pathol Med. 2006 Apr;35(4):244-8. [Medline: 16519773] [doi: 10.1111/j.1600-0714.2006.00411.x]

28. Kalk WW, Vissink A, Stegenga B, Bootsma H, Nieuw Amerongen AV, Kallenberg CG. Sialometry and sialochemistry: a non-invasive approach for diagnosing Sjögren's syndrome. Ann Rheum Dis. 2002 Feb;61(2):137-44. [Medline: 11796400] [doi: 10.1136/ard.61.2.137] [FREE Full Text]

29. Eliasson L, Carlén A. An update on minor salivary gland secretions. Eur J Oral Sci. 2010 Oct;118(5):435-42. Epub 2010 Aug 24. Review. [Medline: 20831576] [doi: 10.1111/j.1600-0722.2010.00766.x]

30. Flink H, Tegelberg A, Lagerlöf F. Influence of the time of measurement of unstimulated human whole saliva on the diagnosis of hyposalivation. Arch Oral Biol. 2005 Jun;50(6):553-9. Epub 2004 Dec 15. [Medline: 15848148] [doi: 10.1016/j.archoralbio.2004.10.015]

31. Valdez IH, Fox PC. Diagnosis and management of salivary dysfunction. Crit Rev Oral Biol Med. 1993;4(3-4):271-7. Review. [Medline: 8373984] [doi: 10.1177/10454411930040030301]

32. Schortinghuis J, Pijpe J, Spijkervet FK, Vissink A. Retention of lipiodol after parotid gland sialography. Int J Oral Maxillofac Surg. 2009 Apr;38(4):346-9. Epub 2009 Jan 20. [Medline: 19157783] [doi: 10.1016/j.ijom.2008.12.007]

33. Kalk WW, Vissink A, Spijkervet FK, Bootsma H, Kallenberg CG, Roodenburg JL. Parotid sialography for diagnosing Sjögren syndrome. Oral Surg Oral Med Oral Pathol Oral Radiol Endod. 2002 Jul;94(1):131-7. [Medline: 12193907] [doi: $10.1067 /$ moe.2002.126017]

34. Rubin P, Holt J. Secretory sialography in diseases of the major salivary glands. Am J Roentgenol Radium Ther Nucl Med. 1957 Apr;77(4):575-98. [Medline: 13411334]

35. Vinagre F, Santos MJ, Prata A, da Silva JC, Santos AI. Assessment of salivary gland function in Sjögren's syndrome: the role of salivary gland scintigraphy. Autoimmun Rev. 2009 Jul;8(8):672-6. Epub 2009 Feb 24. Review. [Medline: 19245858] [doi: 10.1016/j.autrev.2009.02.027]

36. Schall GL, Anderson LG, Wolf RO, Herdt JR, Tarpley TM Jr, Cummings NA, Zeiger LS, Talal N. Xerostomia in Sjögren's syndrome. Evaluation by sequential salivary scintigraphy. JAMA. 1971 Jun 28;216(13):2109-16. [Medline: 4932139] [doi: 10.1001/jama.1971.03180390021005]

37. Ramos-Casals M, Brito-Zerón P, Perez-DE-Lis M, Diaz-Lagares C, Bove A, Soto MJ, Jimenez I, Belenguer R, Siso A, Muxí A, Pons F. Clinical and prognostic significance of parotid scintigraphy in 405 patients with primary Sjogren's syndrome. J Rheumatol. 2010 Mar;37(3):585-90. Epub 2010 Jan 15. [Medline: 20080906] [doi: 10.3899/jrheum.090835]

38. Güne SE, Yilmaz S, Karalezli A, Aktaş A. Quantitative and visual evaluation of salivary and thyroid glands in patients with primary Sjögren's syndrome using salivary gland scintigraphy: relationship with clinicopathological features of salivary, lacrimal and thyroid glands. Nucl Med Commun. 2010 Jul;31(7):666-72 [Medline: 20545046] [doi: 10.1097/MNM.0b013e328339bdf6]

39. Kang J, Jang S, Lee W, Jang S, Lee Y, Kim S. Evaluation of salivary gland dysfunction using salivary gland scintigraphy in Sjögren's syndrome patients and in thyroid cancer patients after radioactive iodine therapy. Nucl Med Mol Imaging. 2011;45(3):161-8. [doi: 10.1007/s13139-011-0091-y] 
40. Niemelä RK, Takalo R, Pääkkö E, Suramo I, Päivänsalo M, Salo T, Hakala M. Ultrasonography of salivary glands in primary Sjogren's syndrome. A comparison with magnetic resonance imaging and magnetic resonance sialography of parotid glands. Rheumatology (Oxford). 2004 Jul;43(7):875-9. Epub 2004 Apr 27. [Medline: 15113992] [doi: 10.1093/rheumatology/keh187] [FREE Full Text]

41. van den Berg I, Pijpe J, Vissink A. Salivary gland parameters and clinical data related to the underlying disorder in patients with persisting xerostomia. Eur J Oral Sci. 2007 Apr;115(2):97-102. [Medline: 17451498] [doi: 10.1111/j.1600-0722.2007.00432.x]

42. Roberts C, Parker GJ, Rose CJ, Watson Y, O'Connor JP, Stivaros SM, Jackson A, Rushton VE. Glandular function in Sjögren syndrome: assessment with dynamic contrast-enhanced MR imaging and tracer kinetic modeling--initial experience. Radiology. 2008 Mar;246(3):845-53. Epub 2008 Jan 30. [Medline: 18235107] [doi: 10.1148/radiol.2463070298] [FREE Full Text]

43. Varghese JC, Thornton F, Lucey BC, Walsh M, Farrell MA, Lee MJ. A prospective comparative study of MR sialography and conventional sialography of salivary duct disease. AJR Am J Roentgenol. 1999 Dec;173(6):1497-503. [Medline: 10584790] [FREE Full Text]

44. Ohbayashi N, Yamada I, Yoshino N, Sasaki T. Sjögren syndrome: comparison of assessments with MR sialography and conventional sialography. Radiology. 1998 Dec;209(3):683-8. [Medline: 9844659]

45. Morimoto Y, Habu M, Tomoyose T, Ono K, Tanaka T, Yoshioka I, Tominaga K, Yamashita Y, Ansai T, Kito S, Okabe S, Takahashi T, Takehara T, Fukuda J, Inenaga K, Ohba T. Dynamic magnetic resonance sialography as a new diagnostic technique for patients with Sjögren's syndrome. Oral Dis. 2006 Jul;12(4):408-14. [Medline: 16792727] [doi: $10.1111 / \mathrm{j} .1601-0825.2005 .01215 . \mathrm{x}$ ]

46. Tanaka T, Ono K, Ansai T, Yoshioka I, Habu M, Tomoyose T, Yamashita Y, Nishida I, Oda M, Kuroiwa H, WakasugiSato N, Okabe S, Kito S, Takahashi T, Tominaga K, Inenaga K, Morimoto Y. Dynamic magnetic resonance sialography for patients with xerostomia. Oral Surg Oral Med Oral Pathol Oral Radiol Endod. 2008 Jul;106(1):115-23. Epub 2008 May 27. [Medline: 18504153] [doi: 10.1016/j.tripleo.2008.03.012]

47. Bialek EJ, Jakubowski W, Zajkowski P, Szopinski KT, Osmolski A. US of the major salivary glands: anatomy and spatial relationships, pathologic conditions, and pitfalls. Radiographics. 2006 May-Jun;26(3):745-63. Review. [Medline: 16702452] [doi: 10.1148/rg.263055024]

48. Wernicke D, Hess H, Gromnica-Ihle E, Krause A, Schmidt WA. Ultrasonography of salivary glands -- a highly specific imaging procedure for diagnosis of Sjögren's syndrome. J Rheumatol. 2008 Feb;35(2):285-93. Epub 2008 Jan 15. [Medline: 18203316]

49. Milic V, Petrovic R, Boricic I, Radunovic G, Marinkovic-Eric J, Jeremic P, Damjanov N. Ultrasonography of major salivary glands could be an alternative tool to sialoscintigraphy in the American-European classification criteria for primary Sjogren's syndrome. Rheumatology (Oxford). 2012 Feb 1. [Epub ahead of print] [Medline: 22302061] [doi: 10.1093/rheumatology/ker431].

50. Takagi Y, Kimura Y, Nakamura H, Sasaki M, Eguchi K, Nakamura T. Salivary gland ultrasonography: can it be an alternative to sialography as an imaging modality for Sjogren's syndrome? Ann Rheum Dis. 2010 Jul;69(7):1321-4. Epub 2010 May 24. [Medline: 20498211] [doi: 10.1136/ard.2009.123836]

51. Ryu OH, Atkinson JC, Hoehn GT, Illei GG, Hart TC. Identification of parotid salivary biomarkers in Sjogren's syndrome by surface-enhanced laser desorption/ionization time-of-flight mass spectrometry and two-dimensional difference gel electrophoresis. Rheumatology (Oxford). 2006 Sep;45(9):1077-86. Epub 2006 Mar 7. [Medline: 16522680] [doi: 10.1093/rheumatology/kei212] [FREE Full Text]

52. Hu S, Wang J, Meijer J, Ieong S, Xie Y, Yu T, Zhou H, Henry S, Vissink A, Pijpe J, Kallenberg C, Elashoff D, Loo JA, Wong DT. Salivary proteomic and genomic biomarkers for primary Sjögren's syndrome. Arthritis Rheum. 2007 Nov;56(11):3588-600. [Medline: 17968930] [doi: 10.1002/art.22954] [FREE Full Text]

53. Fleissig Y, Deutsch O, Reichenberg E, Redlich M, Zaks B, Palmon A, Aframian DJ. Different proteomic protein patterns in saliva of Sjögren's syndrome patients. Oral Dis. 2009 Jan;15(1):61-8. Epub 2008 Oct 9. [Medline: 18939961] [doi: 10.1111/j.1601-0825.2008.01465.x]

54. Ferraccioli G, De Santis M, Peluso G, Inzitari R, Fanali C, Bosello SL, Iavarone F, Castagnola M. Proteomic approaches to Sjögren's syndrome: a clue to interpret the pathophysiology and organ involvement of the disease. Autoimmun Rev. 2010 Jul;9(9):622-6. Epub 2010 May 10. Review. [Medline: 20462525] [doi: 10.1016/j.autrev.2010.05.010]

55. Castagnola M, Cabras T, Iavarone F, Fanali C, Nemolato S, Peluso G, Bosello SL, Faa G, Ferraccioli G, Messana I. The human salivary proteome: a critical overview of the results obtained by different proteomic platforms. Expert Rev Proteomics. 2012;9(1):33-46. [Medline: 22292822] [doi: 10.1586/epr.11.77]

56. Pedersen AM, Bardow A, Nauntofte B. Salivary changes and dental caries as potential oral markers of autoimmune salivary gland dysfunction in primary Sjogren's syndrome. BMC Clin Pathol. 2005 Mar 1;5(1):4. [Medline: 15740617] [doi: 10.1186/1472-6890-5-4] [FREE Full Text] 
57. Gannot G, Lancaster HE, Fox PC. Clinical course of primary Sjögren's syndrome: salivary, oral, and serologic aspects. J Rheumatol. 2000 Aug;27(8):1905-9. [Medline: 10955331]

58. Ramos-Casals M, Font J, Garcia-Carrasco M, Brito MP, Rosas J, Calvo-Alen J, Pallares L, Cervera R, Ingelmo M. Primary Sjögren syndrome: hematologic patterns of disease expression. Medicine (Baltimore). 2002 Jul;81(4):281-92. Review.. [Medline: 12169883] [doi: 10.1097/00005792-200207000-00004]

59. Ramos-Casals M, Font J. Primary Sjögren's syndrome: current and emergent aetiopathogenic concepts. Rheumatology (Oxford). 2005 Nov;44(11):1354-67. Epub 2005 Jun 14. Review. [Medline: 15956090] [doi: 10.1093/rheumatology/keh714] [FREE Full Text]

60. Satoh M, Vázquez-Del Mercado M, Chan EK. Clinical interpretation of antinuclear antibody tests in systemic rheumatic diseases. Mod Rheumatol. 2009;19(3):219-28. Epub 2009 Mar 10. Review. [Medline: 19277826] [doi: 10.1007/s10165-009-0155-3] [FREE Full Text]

61. Huo AP, Lin KC, Chou CT. Predictive and prognostic value of antinuclear antibodies and rheumatoid factor in primary Sjogren's syndrome. Int J Rheum Dis. 2010 Feb 1;13(1):39-47.. [Medline: 20374383] [doi: 10.1111/j.1756-185X.2009.01444.X]

62. Peen E, Mellbye OJ, Haga HJ. IgA rheumatoid factor in primary Sjogren's syndrome. Scand J Rheumatol. 2009 JanFeb;38(1):46-9. [Medline: 18942022] [doi: 10.1080/03009740802366043]

63. Franceschini F, Cavazzana I. Anti-Ro/SSA and La/SSB antibodies. Autoimmunity. 2005;38(1):55-63. [doi: 10.1080/08916930400022954]

64. Nakamura H, Kawakami A, Hayashi T, Iwamoto N, Okada A, Tamai M, Yamasaki S, Ida H, Eguchi K. Anti-centromere antibody-seropositive Sjögren's syndrome differs from conventional subgroup in clinical and pathological study. BMC Musculoskelet Disord. 2010 Jul 1;11:140. [Medline: 20591195] [doi: 10.1186/1471-2474-11-140] [FREE Full Text]

65. Witte T, Matthias T, Arnett FC, Peter HH, Hartung K, Sachse C, Wigand R, Braner A, Kalden JR, Lakomek HJ, Schmidt RE. IgA and IgG autoantibodies against alpha-fodrin as markers for Sjögren's syndrome. Systemic lupus erythematosus. J Rheumatol. 2000 Nov;27(11):2617-20. [Medline: 11093442]

66. Sumida T, Tsuboi H, Iizuka M, Nakamura Y, Matsumoto I. Functional role of M3 muscarinic acetylcholine receptor (M3R) reactive T cells and anti-M3R autoantibodies in patients with Sjögren's syndrome. Autoimmun Rev. 2010 Jul;9(9):615-7. Epub 2010 May 10. Review. [Medline: 20462524] [doi: 10.1016/j.autrev.2010.05.008]

67. Ioannidis JP, Vassiliou VA, Moutsopoulos HM. Long-term risk of mortality and lymphoproliferative disease and predictive classification of primary Sjögren's syndrome. Arthritis Rheum. 2002 Mar;46(3):741-7. [Medline: 11920410] [doi: 10.1002/art.10221]

68. Solans-Laqué R, López-Hernandez A, Bosch-Gil JA, Palacios A, Campillo M, Vilardell-Tarres M. Risk, predictors, and clinical characteristics of lymphoma development in primary Sjögren's syndrome. Semin Arthritis Rheum. 2011 Dec;41(3):415-23. Epub 2011 Jun 12. [Medline: 21665245] [doi: 10.1016/j.semarthrit.2011.04.006]

\section{To cite this article:}

Gomes PD, Juodzbalys G, Fernandes MH, Guobis Z. Diagnostic Approaches to Sjögren's Syndrome: a Literature Review and Own Clinical Experience.

J Oral Maxillofac Res 2012;3(1):e3

URL: http://www.ejomr.org/JOMR/archives/2012/1/e3/v3n1e3ht.pdf

doi: $10.5037 /$ jomr.2012.3103

Copyright $($ C Gomes PD, Juodzbalys G, Fernandes MH, Guobis Z. Accepted for publication in the JOURNAL OF ORAL \& MAXILLOFACIAL RESEARCH (http://www.ejomr.org), 20 March 2012

This is an open-access article, first published in the JOURNAL OF ORAL \& MAXILLOFACIAL RESEARCH, distributed under the terms of the Creative Commons Attribution-Noncommercial-No Derivative Works 3.0 Unported License, which permits unrestricted non-commercial use, distribution, and reproduction in any medium, provided the original work and is properly cited. The copyright, license information and link to the original publication on (http://www.ejomr.org) must be included. 